\title{
Cost, quality, and value in coronary artery bypass grafting
}

\author{
Ruben L. Osnabrugge, MSc, ${ }^{a}$ Alan M. Speir, MD, ${ }^{b}$ Stuart J. Head, PhD, ${ }^{\text {a }}$ Philip G. Jones, MS, \\ Gorav Ailawadi, MD, ${ }^{\mathrm{d}}$ Clifford E. Fonner, BA, ${ }^{\mathrm{e}, \mathrm{f}}$ Edwin Fonner, Jr, DrPH,
}

A. Pieter Kappetein, $\mathrm{MD}, \mathrm{PhD},{ }^{\mathrm{a}}$ and Jeffrey B. Rich, $\mathrm{MD}^{\mathrm{g}}$

\begin{abstract}
Objective: Pay-for-performance measures, part of the Affordable Care Act, aim to reduce health care costs by linking value with Medicare payments, but until now the concept of value has not been applied to specific procedures. We sought to define value in coronary artery bypass grafting (CABG) and provide a framework to identify high-value centers.
\end{abstract}

Methods: In a multiinstitutional statewide database, clinical patient-level data from 42,839 patients undergoing CABG were matched with cost data. Hierarchical models adjusting for relevant preoperative patient characteristics and comorbidities were used to estimate center-specific risk-adjusted costs and risk-adjusted postoperative length of stay. Variation in value across centers was assessed by the correlation between risk-adjusted measures of quality (mortality, morbidity/mortality) and resource use (costs and length of stay).

Results: There were no significant correlations between risk-adjusted costs and risk-adjusted mortality $(\mathrm{r}=0.20, P=.45)$ or morbidity/mortality $(\mathrm{r}=0.15, P=.57)$ across centers. Risk-adjusted costs and length of stay were not significantly associated $(\mathrm{r}=0.23, P=.37)$ because of cost accounting differences across centers. This may explain the lack of correlation between risk-adjusted quality and risk-adjusted cost measures. When risk-adjusted length of stay and morbidity/mortality were used for the framework, there was a strong positive correlation $(\mathrm{r}=0.67, P=.003)$, indicating that higher risk-adjusted quality is associated with shorter risk-adjusted length of stay.

Conclusions: Risk-adjusted length of stay and risk-adjusted combined morbidity/mortality are important outcome measures for assessing value in cardiac surgery. The proposed framework can be used to define value in CABG and identify high-value centers, thereby providing information for quality improvement and pay-for-performance initiatives. (J Thorac Cardiovasc Surg 2014;148:2729-35)

\section{Supplemental material is available online.}

The soaring costs of the US health care system are an increasing burden on society and threaten the financial stability of the government. Currently, health care expenditures represent $10 \%$ to $12 \%$ of the gross domestic product in many western European countries and Canada; this

\footnotetext{
From the Erasmus University Medical Center, ${ }^{a}$ Rotterdam, The Netherlands; Inova Heart and Vascular Institute, ${ }^{\mathrm{b}}$ Fairfax, Va; Saint Luke's Mid America Heart Institute, ${ }^{\mathrm{c}}$ Kansas City, Mo; University of Virginia Health System, ${ }^{\mathrm{d}}$ Charlottesville, Va; ARMUS Corporation, ${ }^{\mathrm{e}}$ San Mateo, Calif; Virginia Cardiac Surgery Quality Initiative, ${ }^{\mathrm{f}}$ Falls Church, Va; and Sentara Heart Hospital, ${ }^{\mathrm{g}}$ Norfolk, Va.

Disclosures: A. Speir has served as consultant/advisory board member for Medtronic, Inc; C.E. Fonner is a former employee of the database manager, ARMUS Corporation; G. Ailawadi has served as consultant/advisory board member for Edwards Lifesciences, Mitralign, Abbott, and has received speaker's honoraria from Atricure. J. Rich has received an education grant from Medtronic. All other authors have nothing to disclose with regard to commercial support.

Received for publication March 12, 2014; revisions received July 2, 2014; accepted for publication July 13, 2014; available ahead of print Sept 16, 2014.

Address for reprints: Jeffrey B. Rich, MD, 1325 N Bay Shore Dr, Virginia Beach, VA 23451 (E-mail: jeffrich2014@cox.net).

$0022-5223 / \$ 36.00$

Copyright (c) 2014 by The American Association for Thoracic Surgery

http://dx.doi.org/10.1016/j.jtcvs.2014.07.089
}

proportion is nearly $18 \%$ (almost US $\$ 3$ trillion) in the United States. ${ }^{1,2}$ There is wide consensus that we must contain health care expenditure while improving quality, and numerous approaches focusing on value have been proposed. $^{3,4}$ Pay-for-performance measures and valuebased payment modifiers, to be implemented in 2015 as part of the Affordable Care Act, aim to reduce health care costs by linking quality and resource use performance measures with Medicare payments to physicians and hospitals. Physicians will be held accountable for resource utilization and costs for their hospitalized patients.

With more than 200,000 costly procedures performed in the United States annually, coronary artery bypass grafting $(\mathrm{CABG})$ is an important procedure for improving health care value. ${ }^{5}$ Value can be defined by a combination of clinical quality and resource use and should use risk-adjusted measures. ${ }^{4,6}$ Although comparisons in efficiency exist ${ }^{7}$ and quality assessment measures have been proposed, ${ }^{8-10}$ the concept of value (combining risk-adjusted measures of resource use and quality) has not been applied to specific procedures like $\mathrm{CABG}$.

We conducted a study to define value in $\mathrm{CABG}$ and to provide a framework to identify high-value centers. By adjusting for relevant preoperative patient characteristics and comorbidities, we derived measures of risk-adjusted 


\begin{tabular}{|ll|}
\hline $\begin{array}{l}\text { Abbreviations and Acronyms } \\
\text { CABG }\end{array}$ & $=$ coronary artery bypass grafting \\
CMS & Centers for Medicare and Medicaid \\
& Services \\
STS & $=$ Society of Thoracic Surgeons \\
STS-PROM $=$ & Society of Thoracic Surgeons- \\
& predicted risk of mortality \\
STS-PROMM = & Society of Thoracic Surgeons- \\
& predicted risk of morbidity or \\
& mortality \\
UB & Uniform billing \\
VCSQI & $=$ Virginia Cardiac Surgery Quality \\
& Initiative
\end{tabular}

resource use and risk-adjusted quality after CABG. Subsequently, we tested whether higher risk-adjusted quality was correlated with shorter risk-adjusted length of stay and lower risk-adjusted costs.

\section{METHODS}

The Virginia Cardiac Surgery Quality Initiative (VCSQI) database was used for this analysis. Clinical records of patients undergoing cardiac surgery were collected prospectively and all primary isolated CABGs between January 2003 and April 2013 were selected for the current study.

VCSQI is a voluntary group of 17 cooperating cardiac surgery centers in the Commonwealth of Virginia. ${ }^{11}$ The aim of the consortium is to improve the quality of cardiac surgical care, while reducing costs. The database covers $\sim 100 \%$ of all cardiac surgical procedures in the state. VCSQI members contribute their data to the Society of Thoracic Surgeons (STS) Adult Cardiac Database. Each of VCSQI's centers agreed to share deidentified patient data for secondary research and quality improvement. Institutional review boards at each participating center exempted this study because it represents a secondary analysis of the VCSQI data registry in the absence of Health Insurance Portability and Accountability Act patient identifiers. Business Associates Agreements are in place between VCSQI, its 17 members, and the database vendor (ARMUS Corporation, San Mateo, Calif).

\section{Clinical Data}

Postoperative outcomes were routinely collected in the STS database and included death, stroke, renal failure, atrial fibrillation, deep sternal wound infection, permanent stroke, prolonged ventilation, and reoperations for bleeding, graft occlusion, and other reasons, all defined according to the STS database definitions. ${ }^{12}$ Operative death was defined as death within 30 days after discharge or within the hospital stay. Preoperative risk was assessed using the STS-predicted risk of mortality (STS-PROM) and the STS-predicted risk of morbidity or mortality (STS-PROMM). Each center was responsible for coding and submitting its data to VCSQI and agreed on the definitions, data collection, and timely submission.

\section{Cost Data}

Patient-level clinical and financial data in the VCSQI database were combined as previously described. ${ }^{13,14}$ Briefly, STS patient records were matched with uniform billing (UB) discharge records. The UB-04 form is used throughout the United States and represents the patient's final hospital bill. Charges for all of the ICD-9 (International Classification of Diseases, ninth revision) revenue codes were grouped into 20 logical cost categories (Table E1). Because charges reflect institutional pricing decisions and other factors unrelated to resource use, we applied cost-to-charge ratios. ${ }^{15}$ These ratios were updated annually and were specific for each participating institution and category within that institution. The total costs estimate was the sum of all 20 categories. The variation in total costs and postoperative length of stay as a result of postoperative complications was reflected in the total estimate for the individual patient. ${ }^{14}$ The medical care service component of the US consumer price index was used to convert all costs to US dollars for the year 2013. . $^{13,16}$

\section{Statistical Analysis}

We calculated risk-adjusted costs and postoperative length of stay for each of the 17 centers by adjusting for differences in the patient case mix. Risk-adjusted estimates were derived from hierarchical models, which account for clustering of outcomes within hospitals, provide more stable estimates for hospitals with low volumes, and adjust for multiplicity of comparisons. This approach to risk standardization has been gaining increasing traction in recent years and has been adopted by Centers for Medicare and Medicaid Services (CMS). ${ }^{17}$ We modeled cost and postoperative length of stay as dependent variables, applying hierarchical generalized linear models, with a gamma distribution for costs and a negative binomial distribution for length of stay. ${ }^{18}$ These models included a random effect for hospital and adjustment for preoperative patient characteristics and comorbidities (Table E2). Given the iterative modeling and large number of variables included, only variables that were significant at a level of $P \leq .01$ were preserved in the models. ${ }^{19}$ The variables age, gender, and race were forced into the models. The models were recently validated for prediction of postoperative length of stay and costs. ${ }^{19}$ Regressions were estimated in $\log$ and linear form, and reported in linear form, because there were no substantial differences in the results and linear regression coefficients are more easily interpreted.

Hospital mean risk-adjusted costs were derived by calculating the ratio of average model-predicted costs for a given hospital to the expected costs based only on patient characteristics, and then multiplying this ratio by the average cost of the overall population. Hospital mean risk-adjusted lengths of stay were calculated in a similar way. ${ }^{20-22}$ Risk-adjusted measures of mortality and morbidity/mortality were also calculated per center, based on validated STS risk calculators.

Morbidity/mortality was defined as postoperative deep sternal wound infection, reoperation, permanent stroke, prolonged ventilation, renal failure or operative mortality. ${ }^{8,9,12}$ Correlation between risk-adjusted quality and resource use measures were assessed with the Spearman correlation coefficient. Analyses were performed using Excel 2010 (Microsoft, Redmond, Wash) and SPSS version 20.0.0 (SPSS, Chicago, Ill), and the hierarchical models were fitted using the GLIMMIX macro in SAS 9.3 (SAS Institute, Inc, Cary, NC).

\section{RESULTS}

The patient characteristics and comorbidities of the 42,839 patients who underwent CABG are presented in Table 1. The STS-PROM averaged $2.2 \%$ and the STSPROMM was $13.8 \%$. Postoperative clinical outcomes and resource use are presented in Table 2. Atrial fibrillation was the most common postoperative complication $(17.2 \%)$, followed by prolonged ventilation $(9.3 \%)$ and renal failure $(3.5 \%)$. Mean total length of stay was 9.3 days, most of which consisted of postoperative stay (6.9 days). The mean total costs for CABG were US\$38,848.

There was significant variation in risk-adjusted costs (US\$27,380-55,296), risk-adjusted postoperative length of stay (6.26-8.77 days), risk-adjusted mortality $(0.95 \%-2.13 \%)$, and risk-adjusted morbidity/mortality 
TABLE 1. Patient characteristics

\begin{tabular}{|c|c|}
\hline Characteristic & $N=42,839$ \\
\hline Age, $y \pm S D$ & $64.0 \pm 10.7$ \\
\hline Male sex, $\%$ & 73.7 \\
\hline STS-PROM & $2.17 \pm 3.7$ \\
\hline STS-PROMM & $13.80 \pm 10.6$ \\
\hline \multicolumn{2}{|l|}{ Race, $\%$} \\
\hline White & 81.5 \\
\hline African American & 13.8 \\
\hline Hispanic & 0.8 \\
\hline Asian & 2.4 \\
\hline Native American & 0.1 \\
\hline Other & 1.4 \\
\hline Body mass index, $\mathrm{kg} / \mathrm{m}^{2}$ & $29.4 \pm 5.7$ \\
\hline Heart failure $\leq 2 \mathrm{wk}$ before, $\%$ & 12.0 \\
\hline Renal failure requiring dialysis, $\%$ & 2.3 \\
\hline Creatinine, $\mathrm{mg} / \mathrm{dL}$ & $1.20 \pm 1.0$ \\
\hline Left ventricular ejection fraction & $51.3 \pm 12.5$ \\
\hline \multicolumn{2}{|l|}{ Chronic lung disease, $\%$} \\
\hline No & 82.4 \\
\hline Mild & 10.0 \\
\hline Moderate & 5.0 \\
\hline Severe & 2.5 \\
\hline Cerebrovascular disease, $\%$ & 13.5 \\
\hline Preoperative cardiogenic shock, $\%$ & 1.6 \\
\hline \multicolumn{2}{|l|}{ Urgency status, $\%$} \\
\hline Elective & 41.5 \\
\hline Urgent & 54.9 \\
\hline Emergency & 3.6 \\
\hline On inotropic medication, $\%$ & 1.6 \\
\hline Arrhythmia, \% & 7.5 \\
\hline Myocardial infarction $\leq 21 \mathrm{~d}, \%$ & 29.0 \\
\hline Peripheral arterial disease, $\%$ & 14.2 \\
\hline Hypertension, $\%$ & 81.4 \\
\hline Diabetes mellitus, $\%$ & 39.6 \\
\hline Immunocompromised status, $\%$ & 2.1 \\
\hline Previous CABG, $\%$ & 3.2 \\
\hline Previous valve operation, $\%$ & 0.2 \\
\hline Previous PCI, \% & 18.7 \\
\hline \multicolumn{2}{|l|}{ No. of diseased vessels, $\%$} \\
\hline 1 & 4.2 \\
\hline 2 & 17.6 \\
\hline 3 & 78.1 \\
\hline
\end{tabular}

Data defined as the mean \pm standard deviation or \% of patients. $S D$, Standard deviation; STS-PROM, Society of Thoracic Surgeons-Predicted Risk of Mortality; STS-PROMM, Society of Thoracic Surgeons-Predicted Risk of Mortality or Morbidity; $C A B G$, coronary artery bypass grafting; $P C I$, percutaneous coronary intervention.

(10.78\%-19.44\%) across centers. Figure 1, A, presents a plot of risk-adjusted costs versus risk-adjusted mortality, showing that there was no statistically significant correlation between risk-adjusted costs and risk-adjusted mortality $(\mathrm{r}=0.20, P=.45)$. Also when complications were included in the risk-adjusted outcome, we found no statistically significant correlation (risk-adjusted costs vs risk-adjusted morbidity/mortality; $\mathrm{r}=0.15, P=.57$; Figure $1, B$ ).
TABLE 2. Postoperative clinical outcomes and resource use

\begin{tabular}{lc}
\hline \multicolumn{1}{c}{ Variable } & $\mathbf{N}=\mathbf{4 2 , 8 3 9}$ \\
\hline Postoperative ventilation $>24 \mathrm{~h}$ & 9.3 \\
Postoperative renal failure & 3.5 \\
Postoperative pneumonia & 2.9 \\
Postoperative atrial fibrillation & 17.2 \\
Postoperative stroke & 1.4 \\
Postoperative deep sternal wound infection & 0.4 \\
Reoperation bleeding & 1.7 \\
Reoperation other cardiac reasons & 0.8 \\
Reoperation noncardiac reasons & 2.0 \\
Operative mortality & 1.8 \\
Operative morbidity/mortality* & 14.4 \\
Total length of stay, d & $9.3 \pm 7.9$ \\
Postoperative length of stay, d & $6.9 \pm 7.0$ \\
Total costs, US $\$$ SD [median] & 38,848 $\pm 29,299$ [32,397] \\
Data defined as mean \pm SD, or \% of patients. SD, Standard deviation. *Defined as \\
operative deep sternal wound infection, reoperation, permanent stroke, prolonged \\
ventilation, renal failure, or mortality.
\end{tabular}

Figure 2, $A$, presents a plot of risk-adjusted postoperative length of stay and risk-adjusted mortality for the 17 cardiac surgical centers. The correlation between risk-adjusted length of stay and risk-adjusted mortality was not statistically significant $(\mathrm{r}=-0.27, P=.30)$. This suggests that lower mortality is not associated with lower resource use, as measured by postoperative length of stay.

There was a significant positive correlation between the more comprehensive quality outcome measure, riskadjusted morbidity/mortality, and risk-adjusted length of stay $(\mathrm{r}=0.67, P=.003$; Figure $2, B)$. Also when 2 centers with the highest risk-adjusted length of stay were excluded, the correlation remained positive and significant $(\mathrm{r}=0.60$, $P=.02$ ). This suggests that higher quality (low riskadjusted morbidity/mortality) coincides with shorter postoperative length of stay. Those cardiac surgical centers represent high-value CABG. On the contrary, there were also centers in the upper right quadrant that combined high risk-adjusted morbidity/mortality with high risk-adjusted length of stay. This suggests that lower quality, as measured by higher than expected morbidity and mortality, leads to higher resource use, as measured by higher than expected postoperative length of stay. It is these centers that represent low value.

There was no significant correlation between riskadjusted costs and risk-adjusted length of stay across centers $(\mathrm{r}=0.23, P=.37$; Figure 3$)$. Although there were several centers for which the risk-adjusted costs and risk-adjusted length of stay showed a trend (centers $\mathrm{A}, \mathrm{O}$, $\mathrm{B}, \mathrm{I}, \mathrm{J}, \mathrm{P}, \mathrm{L}, \mathrm{E}$, and N), there were also centers (C, K, D, and $\mathrm{M})$ that had risk-adjusted costs that were different than would be expected based on risk-adjusted length of stay. Because length of stay is closely related to costs at a group level, ${ }^{23}$ a strong correlation between risk-adjusted cost and risk-adjusted length of stay was expected. 


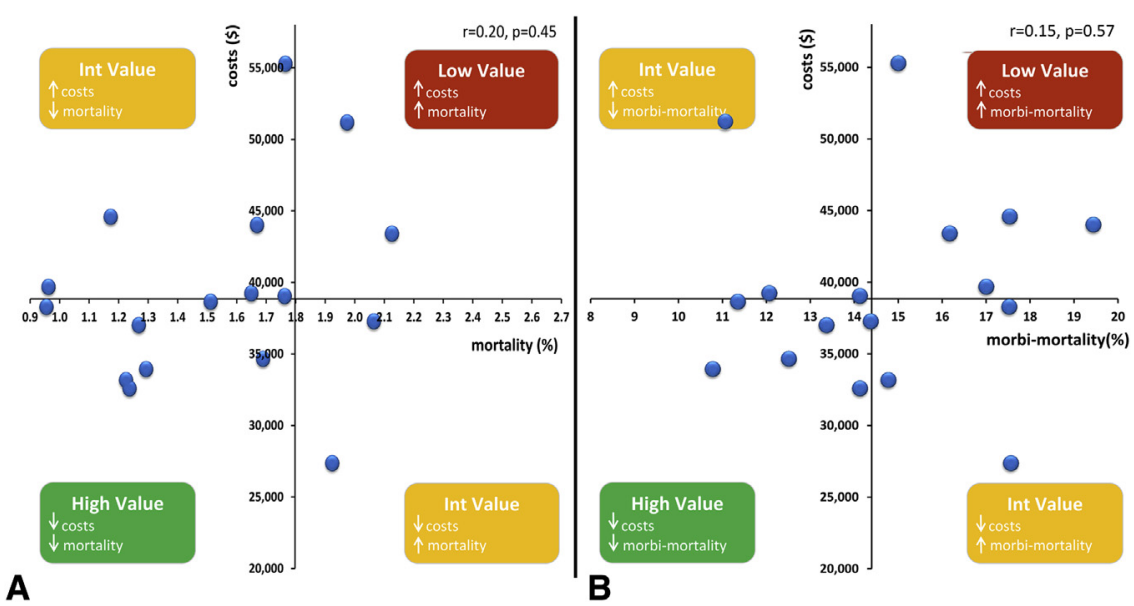

FIGURE 1. Risk-adjusted costs versus risk-adjusted mortality (A) and versus risk-adjusted morbidity/mortality (B) per center. The lack of a statistically significant correlation coefficient indicates that there is no relationship between resource use (risk-adjusted postoperative length of stay) and quality (riskadjusted mortality and risk-adjusted morbidity/mortality). The axes cross at the population average operative mortality (1.80\%) and population average costs (US $\$ 38,848)$. Int, Intermediate; morbi, morbidity.

\section{DISCUSSION}

Even after adjusting for preoperative patient characteristics and comorbidities, we found important variation in measures of quality (risk-adjusted mortality, risk-adjusted morbidity/mortality) and resource use (risk-adjusted costs and risk-adjusted length of stay) across 17 centers performing $\mathrm{CABG}$ in the Commonwealth of Virginia. A significant correlation existed between risk-adjusted morbidity/mortality and risk-adjusted length of stay. These findings suggest that better quality leads to shorter postoperative length of stay and resource use. Substantial savings and better outcomes can be realized if all centers achieve the same performance as high-value centers.

This is the first study to describe combined, centerspecific, clinical, and financial outcomes for CABG. The over- and underperforming centers are shown in the lower left and upper right quadrants in Figure 2, $B$, respectively. The study serves as a basis for discussions on health care value measurement and facilitates improvements of value in health care. Policy measures as pay-for-performance and the value-based payment modifiers provide financial incentives to improve value (ie, to keep costs low by improving outcomes and quality of care). ${ }^{24,25}$ In general, policy measures will provide incentives that relate payment inversely to risk-adjusted clinical outcomes and riskadjusted resource use. In the current study, we found distinct variability in value when both quality and cost measures were combined, but the exact definitions of low/high performers require close collaboration with the physician community before this can lead to real-world payment implications.

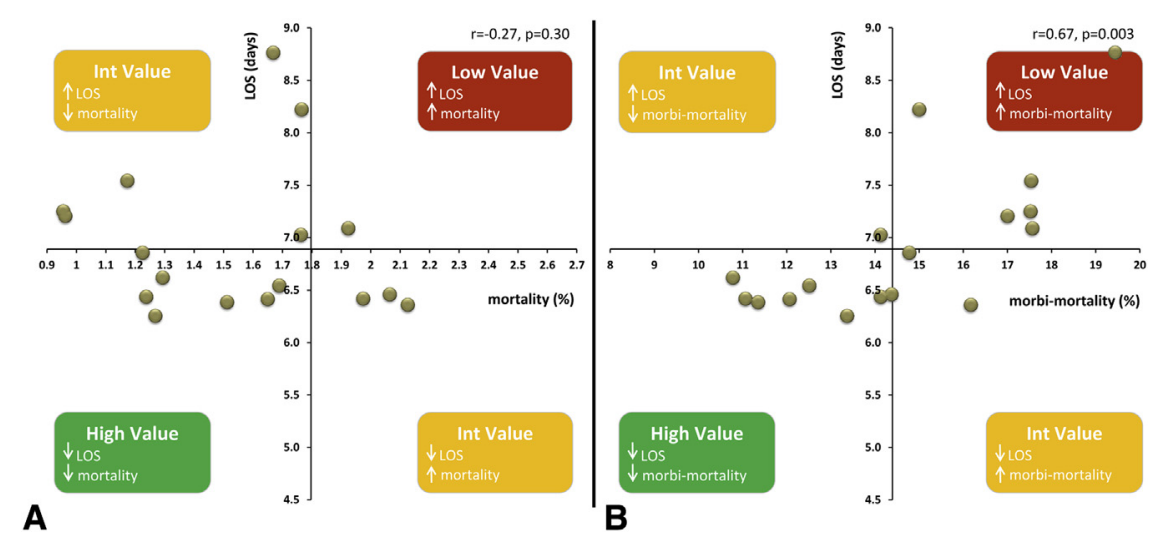

FIGURE 2. Risk-adjusted length of stay versus risk-adjusted mortality (A) and risk-adjusted morbidity/mortality (B) per center. There is no significant correlation between risk-adjusted postoperative length of stay and risk-adjusted mortality. The significant positive correlation coefficient between riskadjusted length of stay and risk-adjusted morbidity/mortality indicates that centers with higher quality (low risk-adjusted morbidity/mortality) are also more efficient (low risk-adjusted length of stay), thereby representing high-value centers. The axes cross at the population average morbidity/mortality $(14.40 \%)$ and population average costs (US\$38,848). Int, Intermediate; LOS, length of stay; morbi, morbidity. 


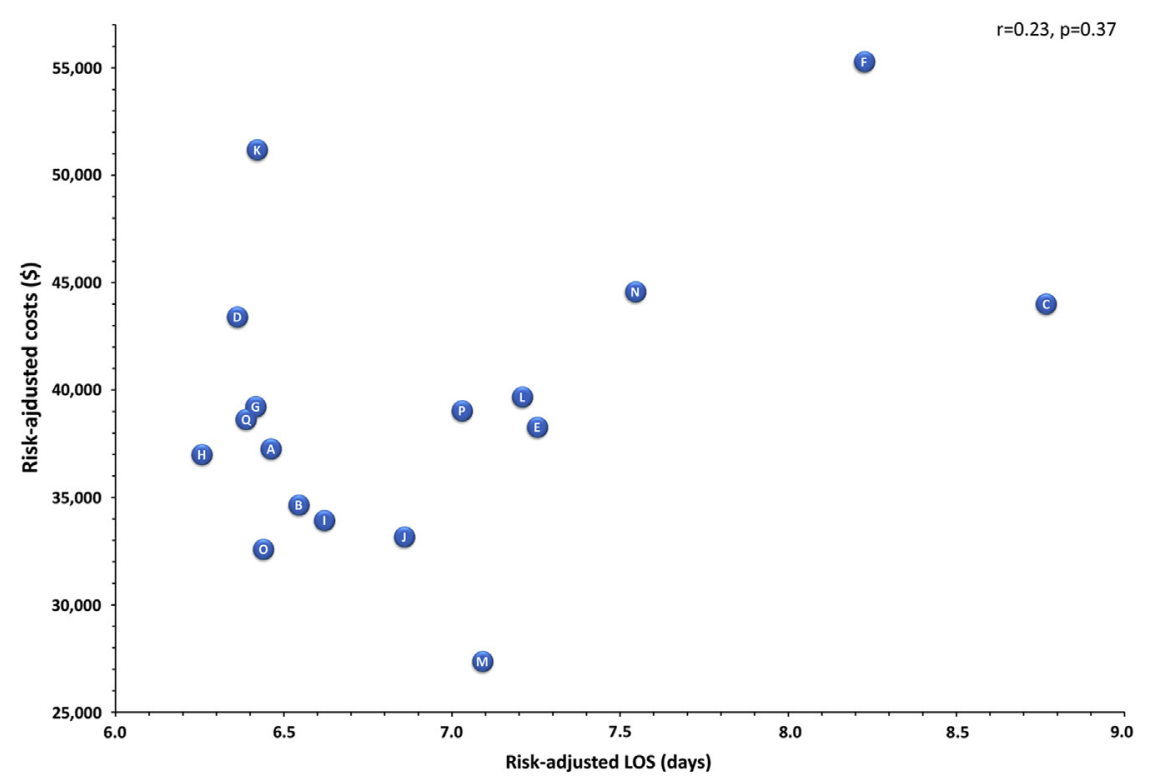

FIGURE 3. Risk-adjusted costs and risk-adjusted length of stay per center. The dots represent the risk-adjusted costs (vertical axis) and risk-adjusted length of stay (horizontal axis) per cardiac surgical center. LOS, Length of stay.

Previous studies on pay-for-performance have been criticized for their performance metrics that focused on processes of care that were not clinically meaningful. ${ }^{26}$ For instance, measuring the proportion of patients with heart failure receiving paper discharge instructions does not necessarily result in better patient outcomes. ${ }^{27}$ In general, physicians, patients, and the CMS should work together to define meaningful outcome measures. Clinically relevant metrics will not only increase the potential of pay-forperformance but are also more likely to engage physicians than process-based metrics. ${ }^{28}$ In the current analyses, we used risk-adjusted costs and risk-adjusted length of stay as measures of resource use, and risk-adjusted mortality and risk-adjusted morbidity/mortality as quality measures.

\section{Outcome Measures for Assessing Value}

Unexpectedly, we only found a strongly significant correlation when risk-adjusted length of stay and risk-adjusted morbidity/mortality were used as outcome measures for resource use and quality, respectively. Because costs and length of stay are closely related at a group level, ${ }^{23}$ we also expected risk-adjusted costs and risk-adjusted morbidity/mortality to be significantly correlated. However, different centers account costs differently, particularly in the way overhead costs are allocated. ${ }^{29} \mathrm{~A}$ center with brand new facilities and high real estate costs may allocate costs differently to a single procedure (CABG) than centers with depreciated facilities and a lower cost location. This is less of an issue when the study objective is to estimate overall costs of a procedure or model building for all centers combined, ${ }^{19}$ but using these cost data to compare centers is likely to reflect the variation in accounting systems instead of true differences in the efficiency of performing CABG. Even with a uniform hospital bill (UB-04) and similar cost accounting systems, it is not clear that the accounting practices are comparable across each of the study centers, because costs of similar resources (catheters, sutures, equipment) might also differ between centers. Ideally, standardized unit costs should be applied to each patient's resource consumption, ${ }^{30}$ but these data were unavailable for this large dataset.

Our alternative measure of risk-adjusted resource use, length of stay, is widely available and easy to measure. Postoperative length of stay as an isolated performance measure (ie, without a risk-adjusted quality measure) should be avoided, because this might lead to overaggressive discharge protocols. ${ }^{31}$ A balanced approach to efficiency and quality improvement will provide a patient centric and patient safe approach to health care. Also, factors beyond a hospital's direct control (eg, the lack of postacute facilities) might influence postoperative length of stay. On the other hand, risk-adjusted length of stay (in combination with risk-adjusted quality) provides incentives for centers to carefully evaluate their processes of care from a broad perspective, including improvements in postdischarge facilities.

We did not find a correlation of risk-adjusted mortality with any measure of risk-adjusted resource use (costs or length of stay). Mortality alone may be an inadequate measure to compare quality across centers and our analyses show that complications are the real driver of the association. Mortality may or may not result in increased resource use because a patient who dies shortly after surgery consumes few resources. Complications on the other hand, always lead to higher resource use consumption. 
Therefore, the STS Quality Measurement Task Force proposes a comprehensive composite quality score, in which risk-adjusted morbidity/mortality is an important domain. ${ }^{8,9}$

After high-value centers have been identified, subsequent in-depth research and comparison with low-value centers is needed to identify factors that help to explain how these centers achieved the exceptional performance on riskadjusted quality and risk-adjusted resource use measures. This process of quality improvement could include qualitative research such as collaborative site visits and structured interviews between the participating centers. ${ }^{8,9}$

\section{Limitations}

This study has some limitations. First, the results of this study may not be generalizable to other cardiac surgical centers in the United States as data were used from 17 cardiac surgical centers in 1 state. However, the key variables (STS-PROMM, length of stay) are well known and therefore, the framework developed in this study can be applied to all cardiac surgical centers in the United States performing CABG. Second, we used postoperative length of stay as a surrogate for resource use because differences in accounting methodology hampered cost comparisons across centers. Ideally, standardized unit costs should be applied to each patient's resource consumption. ${ }^{30}$ However, these detailed individual resource consumption data were unavailable for this large dataset. Instead, we used a single measure of resource use, risk-adjusted length of stay, which is closely related to costs at a group level. ${ }^{23}$ Third, the study is observational, and unmeasured confounding cannot be excluded. However, the risk-adjustment of length of stay and costs using the available variables was robust, and an observational design is best to evaluate actual clinical practice. It is important to realize that centers that treat markedly more frail or other special patients might be unjustifiably categorized as a low-value center.

\section{CONCLUSIONS}

Risk-adjusted length of stay and risk-adjusted combined morbidity/mortality are important outcome measures for assessing value in cardiac surgery. In high-value centers, lower rates of risk-adjusted morbidity/mortality outcomes were associated with shorter risk-adjusted length of stay. The proposed framework can be used to define value in CABG and identify high-value centers, thereby providing useful information for quality improvement and pay-forperformance initiatives.

\section{References}

1. Keehan SP, Cuckler GA, Sisko AM, Madison AJ, Smith SD, Lizonitz JM, et al. National health expenditure projections: modest annual growth until coverage expands and economic growth accelerates. Health Aff (Millwood). 2012;31: 1600-12.
2. OECD Health Statistics. Health expenditure and financing. Available at: http:// stats.oecd.org. Accessed October 16, 2013.

3. Ginsburg PB. Bending the health care cost curve. N Engl J Med. 2012;367: 2454-5.

4. Porter ME. What is value in health care? N Engl J Med. 2010;363:2477-81.

5. Go AS, Mozaffarian D, Roger VL, Benjamin EJ, Berry JD, Blaha MJ, et al. Heart disease and stroke statistics-2014 update: a report from the American Heart Association. Circulation. 2014;129:e28-292.

6. Kilic A, Shah AS, Conte JV, Mandal K, Baumgartner WA, Cameron DE, et al. Understanding variability in hospital-specific costs of coronary artery bypass grafting represents an opportunity for standardizing care and improving resource use. J Thorac Cardiovasc Surg. 2014;147:109-16.

7. Rosenthal GE, Kaboli PJ, Barnett MJ. Differences in length of stay in Veterans Health Administration and other United States hospitals: is the gap closing? Med Care. 2003;41:882-94.

8. O'Brien SM, Shahian DM, DeLong ER, Normand S-LT, Edwards FH, Ferraris VA, et al. Quality measurement in adult cardiac surgery: part 2-statistical considerations in composite measure scoring and provider rating. Ann Thorac Surg. 2007;83:S13-26.

9. Shahian DM, Edwards FH, Ferraris VA, Haan CK, Rich JB, Normand S-LT, et al. Quality measurement in adult cardiac surgery: part 1-conceptual framework and measure selection. Ann Thorac Surg. 2007;83:S3-12.

10. Miyata H, Motomura N, Murakami A, Takamoto S. Effect of benchmarking projects on outcomes of coronary artery bypass graft surgery: challenges and prospects regarding the quality improvement initiative. J Thorac Cardiovasc Surg. 2012;143:1364-9.

11. Rich JB, Speir AM, Fonner E Jr, Virginia Cardiac Surgery Quality Initiative. Making a business case for quality by regional information sharing involving cardiothoracic surgery. Am Heart Hosp J. 2006;4:142-7.

12. Shahian DM, O'Brien SM, Filardo G, Ferraris VA, Haan CK, Rich JB, et al. The Society of Thoracic Surgeons 2008 cardiac surgery risk models: part 1-coronary artery bypass grafting surgery. Ann Thorac Surg. 2009;88:S2-22.

13. Osnabrugge RLJ, Speir AM, Head SJ, Fonner CE, Fonner E Jr, Ailawadi G, et al. Costs for surgical aortic valve replacement according to preoperative risk categories. Ann Thorac Surg. 2013;96:500-6.

14. Speir AM, Kasirajan V, Barnett SD, Fonner E Jr. Additive costs of postoperative complications for isolated coronary artery bypass grafting patients in Virginia. Ann Thorac Surg. 2009;88:40-5.

15. Weinstein MC, Siegel JE, Gold MR, Kamlet MS, Russell LB. Recommendations of the Panel on Cost-effectiveness in Health and Medicine. JAMA. 1996;276: 1253-8.

16. US Bureau of Labor Statistics. Available at: http://www.bls.gov/cpi/. Accessed December 15, 2013.

17. Ash AS, Fienberg SF, Louis TA, Normand S-LT, Stukel TA, Utts J. Statistical issues in assessing hospital performance. Available at: http://www.cms.gov/ Medicare/Quality-Initiatives-Patient-Assessment-Instruments/HospitalQuality Inits/Downloads/Statistical-Issues-in-Assessing-Hospital-Performance.pdf. Accessed November 30, 2013.

18. Goldstein H. Multilevel statistical models. 4th ed. Chichester: John Wiley; 2011.

19. Osnabrugge RL, Speir AM, Head SJ, Jones PG, Ailawadi G, Fonner CE, et al. Prediction of costs and length-of-stay in coronary artery bypass grafting. Ann Thorac Surg. August 7, 2014 [Epub ahead of print].

20. Christiansen CL, Morris CN. Improving the statistical approach to health care provider profiling. Ann Intern Med. 1997;127:764-8.

21. Shahian DM, Torchiana DF, Shemin RJ, Rawn JD, Normand SL. Massachusetts cardiac surgery report card: implications of statistical methodology. Ann Thorac Surg. 2005;80:2106-13.

22. Normand S-LT, Shahian DM. Statistical and clinical aspects of hospital outcomes profiling. Stat Sci. 2007;22:206-26.

23. Riordan CJ, Engoren M, Zacharias A, Schwann TA, Parenteau GL, Durham SJ, et al. Resource utilization in coronary artery bypass operation: does surgical risk predict cost? Ann Thorac Surg. 2000;69:1092-7.

24. Centers for Medicare and Medicaid Services. Value based payment modifier. Available at: http://www.cms.gov/Medicare/Medicare-Fee-for-Service-Payment/ PhysicianFeedbackProgram/ValueBasedPaymentModifier.html. Accessed December 20, 2013.

25. VanLare JM, Blum JD, Conway PH. Linking performance with payment implementing the physician value-based payment modifier. JAMA. 2012;308 2089-90. 
26. Jha AK. Time to get serious about pay for performance. JAMA. 2013;309: 347-8.

27. Werner RM, Dudley RA. Medicare's new hospital value-based purchasing program is likely to have only a small impact on hospital payments. Health Aff (Millwood). 2012;31:1932-40.

28. Centers for Medicare and Medicaid Services. Physician quality reporting system. Available at: http://www.cms.gov/Medicare/Quality-Initiatives-PatientAssessment-Instruments/PQRS/index.html?redirect=/PQRS. Accessed December 20, 2013.
29. Drummond MF, Sculpher MJ, Torrance GW, O’Brien BJ, Stoddart GL. Methods for the economic evaluation of health care programmes. 3rd ed. Oxford: Oxford University Press; 2005.

30. Finkler SA. The distinction between cost and charges. Ann Intern Med. 1982;96: 102-9.

31. Peterson ED, Coombs LP, Ferguson TB, Shroyer AL, DeLong ER, Grover FL, et al. Hospital variability in length of stay after coronary artery bypass surgery: results from the Society of Thoracic Surgeon's National Cardiac Database. Ann Thorac Surg. 2002;74:464-73. 
TABLE E1. Cost categories and ICD-9 revenue codes

\begin{tabular}{lc}
\hline \multicolumn{1}{c}{ Cost category } & Revenue codes \\
\hline Emergency room & $450-459$ \\
ICU/CCU & $200-219$ \\
Regular room & $100-179$ \\
Radiology & $320-359,400-409$ \\
Laboratory & $300-319$ \\
Cardiac diagnostics & $480-489,730-731,739$ \\
Peripheral vascular laboratory & 921 \\
Anesthesia & $370-379$ \\
Operating room & $360-369,490-499$ \\
Recovery room & $710-719$ \\
Blood products & $380-399$ \\
Implants (pacers, ICD, valve) & 275,278 \\
General supplies & $270-274,276-277,279$ \\
Pharmacy & $250-259$ \\
Intravenous & $260-269$ \\
Respiratory therapy & $410-419$ \\
Cardiac catheterization & 481 \\
$\quad$ laboratory & \\
Therapies (PT, OT, cardiac & $420-449$ \\
$\quad$ rehabilitation) & \\
Dialysis & $800-809,820-859,880-889$ \\
Other & $500-679,700-709,740-799,901-920$, \\
& $922-942,944-999$ \\
\hline
\end{tabular}

$I C U$, Intensive care unit; $C C U$, cardiac care unit; $I C D$, implantable cardioverter defibrillator; $P T$, physiotherapy; $O T$, occupational therapy.
TABLE E2. Preoperative patient characteristics and comorbidities for which the cost and length of stay outcomes were adjusted

\begin{tabular}{ll}
\hline \multicolumn{1}{c}{ Cost model } & \multicolumn{1}{c}{ Length of stay model } \\
\hline Age & Age \\
Male sex & Male sex \\
Race & Race \\
Body mass index & Body mass index \\
Heart failure $\leq 2 \mathrm{wk}$ before & Heart failure $\leq 2 \mathrm{wk}$ before \\
Creatinine & Creatinine, mg/dL \\
Left ventricular ejection fraction & Left ventricular ejection fraction \\
Chronic lung disease (mild/ & Chronic lung disease (mild/ \\
$\quad$ moderate/severe) & moderate/severe) \\
Cerebrovascular disease & Cerebrovascular disease \\
Preoperative cardiogenic shock & Preoperative cardiogenic shock \\
Urgency status (urgent/emergency) & Urgency status (urgent/emergency) \\
On inotropic medication & On inotropic medication \\
Arrhythmia & Arrhythmia \\
Myocardial infarction $\leq 21 \mathrm{~d}$ & Myocardial infarction $\leq 21 \mathrm{~d}$ \\
Peripheral arterial disease & Peripheral arterial disease \\
Hypertension & \\
Diabetes mellitus & Diabetes mellitus \\
Immunocompromised status & Immunocompromised status \\
Previous CABG & Previous CABG \\
Previous valve operation & Previous valve operation \\
Previous PCI & \\
No. of diseased vessels (2 or 3$)$ & No. of diseased vessels (2 or 3) \\
\hline$C A B G$, Con & $P C$, percis
\end{tabular}
$C A B G$, Coronary artery bypass grafting; $P C I$, percutaneous coronary intervention. 